\title{
Synthetic nanowire/nanotube-based solid substrates for controlled cell growth
}

\author{
Ku Youn Baik', Sung Young Park², Seon Namgung ${ }^{3}$, Daesan Kim, Dong-guk Cho ${ }^{5}$, Minju Lee ${ }^{5}$ \\ and Seunghun Hong ${ }^{4,5^{*}}$
}

\begin{abstract}
The behaviour of cells can be controlled by various microenvironments such as nanostructured cell-culture substrates with controlled nanotopography and chemical properties. One of promising substrates for controlled cell growth is a solid substrate comprised of synthetic one-dimensional nanostructures such as polymer nanofibers, carbon-based nanotubes/nanofibers, and inorganic nanowires. Such nanotube/nanowire structures have a similar dimension as extracellular matrix fibers, and their nanotopography and chemical properties can be easily controlled, which expands their possible applications in controlling the growth and differentiation of cells. This paper provides a concise review on the recent applications of solid substrates based on synthetic nanowires/nanotubes for controlled cell growth and differentiation.
\end{abstract}

Keywords: Nanowire; Nanotube; Cell adhesion; Cell growth; Cell proliferation; Cell differentiation

\section{Introduction}

Cell behaviors, such as adhesion, proliferation and differentiation, are affected by various microenvironmental factors. Such microenvironments consist of extracellular matrices (ECM) with soluble components such as growth factors and cytokines. In order to create artificial microenvironments, biologically-derived materials have been intensively explored, since they have the advantages of being biocompatible and of having similar mechanical properties as native tissues [1-4].

Recent advances in nanotechnology present new possibilities and strategies in cell therapy and tissue engineering. Synthetic bio-inspired materials have been developed to create new controllable microenvironments rather than just to mimic in-vivo environments [5,6]. Among the synthetic nanomaterials, nanowires and nanotubes have a similar dimension with natural ECM components such as collagen and elastic fibers. The diameter of these nanostructures can be precisely controlled, and they can be aligned, patterned or constructed 3-dimensionally [7]. These properties facilitate mimicking microenvironments

\footnotetext{
* Correspondence: seunghun@snu.ac.kr

${ }^{4}$ Department of Biophysics and Chemical Biology, Seoul National University, Seoul 151-747, Korea

${ }^{5}$ Department of Physics and Astronomy, and Institute of Applied Physics,

Seoul National University, Seoul 151-747, Korea

Full list of author information is available at the end of the article
}

of various tissues. For example, the parallel-alignment of nanowires mimics that of ECMs in tendon and muscle, and concentric whorls in bone and mesh-like lattices of skin.

The well-investigated nanowires/nanotubes can be categorized into three gropus: 1 ) polymer nanofibers, 2) carbon based nanotubes/nanofibers, and 3) inorganic nanowires/nanotubes (Figure 1). These nanowire/nanotube structures have many interesting physical and chemical properties which can be easily modulated (Table 1). Polymer nanofibers are biodegradable, which makes them ideal for tissue regeneration and drug delivery [8]. Carbon-based nanostructures can be easily functionalized by chemical or physical methods to control the degree of cell adsorption [9]. Inorganic nanowires can be utilized as devices for measuring cell adhesion force [10], dynamic drug delivery system [11] and electrical cell sensors [12] due to prominent electrical and mechanical properties.

In this review, we discuss the cell engineering with solid substrates based on synthetic nanowires/nanotubes, especially polymer nanofibers, carbon based nanostructures and inorganic nanowires. The cellular adhesion, proliferation and differentiation on these substrates and various other applications will be discussed.

\section{实}

(c) 2014 Baik et al.; licensee Springer. This is an Open Access article distributed under the terms of the Creative Commons Attribution License (http://creativecommons.org/licenses/by/4.0), which permits unrestricted use, distribution, and reproduction in any medium, provided the original work is properly credited. 


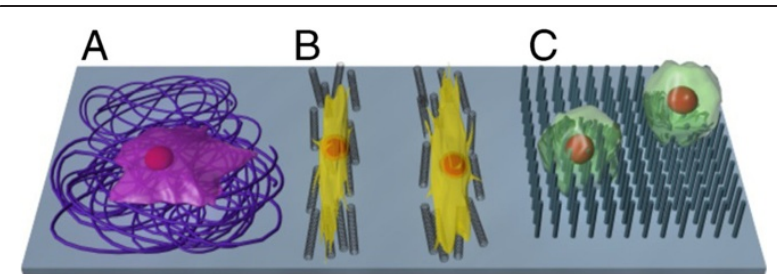

Figure 1 Schematic diagram showing the controlled cell growth on nanowire/nanotube based-substrates. Cells grown on (A) bundles, (B) laterally-aligned patterns, and (C) vertically-aligned structures of nanowires/nanotubes.

\section{Review}

\subsection{Polymer nanofiber-based substrates}

A polymer nanofiber is a one-dimensional nanostructure which is comprised of synthetic small molecules typically connected by covalent chemical bonds. The most important and distinguished property of polymer nanofibers compared to other synthetic nanowires is biodegradability. Taking an advantage of this property, polymer nanofibers can be utilized as an implantable substrate for various applications such as tissue regeneration, local treatment of disease, and drug delivery. Furthermore, polymer nanofibers can be functionalized with various biomaterials such as ECM molecules, ECM analogs and growth factors to enhance cellular functionality, and, thus, it has a great potential in biological and biomedical applications.

Table 1 Overview of properties of synthetic nanowires/nanotubes

\begin{tabular}{|c|c|c|c|c|}
\hline & Materials & Diameter & Controllability & Biomedical applications \\
\hline \multirow[t]{6}{*}{ Polymer nanofibers } & Poly (e-caprolactone) (PCL) & $0.01 \sim 100 \mu \mathrm{m}$ & Diameter & \multirow{6}{*}{$\begin{array}{l}\text { Controlled cell growth (adhesion, } \\
\text { migration, proliferation, differentiation) } \\
{[14-22]}\end{array}$} \\
\hline & Polyaniline (PANi) & & $\begin{array}{l}\text { Structure (aligned, } \\
\text { random) }\end{array}$ & \\
\hline & Poly (L-lactic acid) (PLLA) & & Surface functionalization & \\
\hline & Polyethersulfone (PES) & & Degradation & \\
\hline & \multirow[t]{2}{*}{ Poly (D,L-lactide-co-glycolide) (PLGA) } & & Elasticity & \\
\hline & & & Composition & \\
\hline \multirow{3}{*}{$\begin{array}{l}\text { Carbon-based } \\
\text { nanostructures }\end{array}$} & \multirow{2}{*}{$\begin{array}{l}\text { Signle wall carbon nanotube (swCNT) } \\
\text { multi wall carbon nanotube (mwCNT) }\end{array}$} & \multirow[t]{2}{*}{$1 \sim 2 / 2 \sim 100 \mathrm{~nm}$} & Diameter & \multirow{2}{*}{$\begin{array}{l}\text { Controlled cell growth (adhesion, } \\
\text { migration, proliferation, } \\
\text { differentiation) [26-36] }\end{array}$} \\
\hline & & & $\begin{array}{l}\text { Structure (aligned, } \\
\text { random, vertical) }\end{array}$ & \\
\hline & Carbon nanofiber (CNF) & $3.5 \sim 500 \mathrm{~nm}$ & Surface functionalization & $\begin{array}{l}\text { Controlled cell growth (adhesion, } \\
\text { migration, proliferation, } \\
\text { differentiation) [39-41] }\end{array}$ \\
\hline \multirow[t]{15}{*}{$\begin{array}{l}\text { Inorganic } \\
\text { nanowires/nanotubes }\end{array}$} & \multirow[t]{2}{*}{$\mathrm{TiO}_{2}$ nanotube } & \multirow[t]{2}{*}{$10 \sim 100 \mathrm{~nm}$} & \multirow[t]{2}{*}{ Diameter } & $\begin{array}{l}\text { Controlled cell growth (adhesion, } \\
\text { proliferation, differentiation) [46-48] }\end{array}$ \\
\hline & & & & Orthopaedic implant [46-48] \\
\hline & \multirow[t]{2}{*}{ ZnO nanowire } & \multirow[t]{2}{*}{$10 \sim 300 \mathrm{~nm}$} & Diameter & \multirow{2}{*}{$\begin{array}{l}\text { Controlled cell growth (adhesion, } \\
\text { proliferation, differentiation) [55-57] }\end{array}$} \\
\hline & & & $\begin{array}{l}\text { Structure (aligned, } \\
\text { random, vertical) }\end{array}$ & \\
\hline & \multirow[t]{2}{*}{ GaP Nanowire } & \multirow[t]{2}{*}{$20 \sim 100 \mathrm{~nm}$} & \multirow[t]{2}{*}{ Diameter } & $\begin{array}{l}\text { Controlled cell growth (adhesion, } \\
\text { proliferation) [59] }\end{array}$ \\
\hline & & & & Mechanosensing [58] \\
\hline & \multirow[t]{3}{*}{ Ni nanowire } & \multirow[t]{3}{*}{$10 \sim 200 \mathrm{~nm}$} & Diameter & \multirow{3}{*}{$\begin{array}{l}\text { Controlled cell growth (adhesion, } \\
\text { separation, positioning) }[60,61]\end{array}$} \\
\hline & & & $\begin{array}{l}\text { Structure (aligned, } \\
\text { random) }\end{array}$ & \\
\hline & & & Magnetic property & \\
\hline & \multirow[t]{2}{*}{ Au nanowire } & \multirow[t]{2}{*}{$3 \sim 100 \mathrm{~nm}$} & Diameter & \multirow{2}{*}{$\begin{array}{l}\text { Controlled cell growth (adhesion, } \\
\text { differentiation) [63] }\end{array}$} \\
\hline & & & Surface functionalization & \\
\hline & \multirow[t]{4}{*}{ Si nanowire } & \multirow[t]{4}{*}{$3 \sim 500 \mathrm{~nm}$} & \multirow[t]{2}{*}{ Diameter } & Mechanosensing [10] \\
\hline & & & & Electrical sensor $[12,43,44]$ \\
\hline & & & $\begin{array}{l}\text { Structure (aligned, } \\
\text { random, vertical) }\end{array}$ & \multirow[t]{2}{*}{ Intracellular delivery [42] } \\
\hline & & & Surface functionalization & \\
\hline
\end{tabular}




\subsubsection{Effect on cell adhesion}

To mimic natural microenvironments for the cell control, various artificial and nanometer-scale structures with different nanotopography have been developed by many groups. For example, fibrous nanostructures can structurally and functionally mimic ECM in biological systems, and they can regulate cell responses. Several groups showed that the proliferation, migration, alignment and gene expression of cells were affected by the alignment and the dimension of nanofibers in contact with cells (Figure $2(\mathrm{~A}-\mathrm{H})$ ).

Patel et al. investigated the combined effects of aligned polymer nanofibers and bioactive factors on cells [13]. Polymer nanofibers were functionalized with laminin and basic fibroblast growth factor (bFGF) to imitate native ECM fibrils. In this research, aligned polymer nanofibers induced longer neurite outgrowth and faster skin cell migration compared with randomly-oriented polymer nanofibers. The cells were elongated, and they migrated along the direction of polymer nanofibers. In addition, growth factors attached to aligned nanofibers were found to be more effective than those in solution on neurite outgrowth.

Yang et al. also examined the effect of nanofiber alignment on the neurite outgrowth of neural stem cells (NSCs) [14]. The aligned nanofibers supported the NSC culture, and they improved the neurite outgrowth (Figure 2 $(\mathrm{E}, \mathrm{F}))$. They also found that microscale polymer fibers have no significant effect on the neurite length. Baker et al. showed that the mechanical properties such as stiffness and elastic modulus of polymer nanofibers based cell-laden constructs depend on the alignment of polymers but not on cell type [15]. Meniscal fibrochondrocytes (MFCs) and mesenchymal stem cells (MSCs) were tested on poly ( $\varepsilon$-caprolactone) (PCL) polymer nanofibers. The tensile properties of aligned polymer nanofiber based cellladen constructs were higher than those of randomly distributed one, whereas both cell-laden constructs were comparable in amount of total DNA and produced ECMs.

The diameter of polymer nanofibers is also an important factor affecting cell adhesion. Li et al. [16] used polyaniline (PANi) and gelatin mixed polymer with different volume ratio. They found that the diameter of PANi-gelatine polymer nanofibers decreased from 803 $\pm 121 \mathrm{~nm}$ to $61 \pm 13 \mathrm{~nm}$ with the decrease of the volume ratio of gelatin (Figure $2(\mathrm{C}, \mathrm{D}))$ ). The $\mathrm{H} 9 \mathrm{c} 2$ rat cardiac myoblasts cultured on randomly distributed polymer fibers showed no significant difference in proliferation, but their morphology varied with the diameter of polymer nanofibers. Cells on thicker nanofibers showed a large number of pseudo-filopodia attachment to nanofibers (Figure $2(\mathrm{G})$ ), while cells on thinner nanofibers spread randomly just as those on glass surface (Figure $2(\mathrm{H})$ ).

\subsubsection{Effect on cell differentiation}

Cell differentiation is the process in which a progenitor cell or a stem cell becomes a more specified cell such as a bone cell, a neural cell, a liver cell, etc. There are soluble (e.g. growth factors, cytokines) and insoluble (e.g. ECM matrix, physical environments) factors which can affect the cell differentiation. Polymer nanofibers have shown the capability of supporting various stem cell differentiations, and they can even enhance the differentiation of the stem cells compared with a conventional scaffold.

Li et al. investigated the in vitro chondrogenic differentiation of MSCs on a PCL nanofiber-based scaffold in the presence of the transforming growth factor, TGF- 31
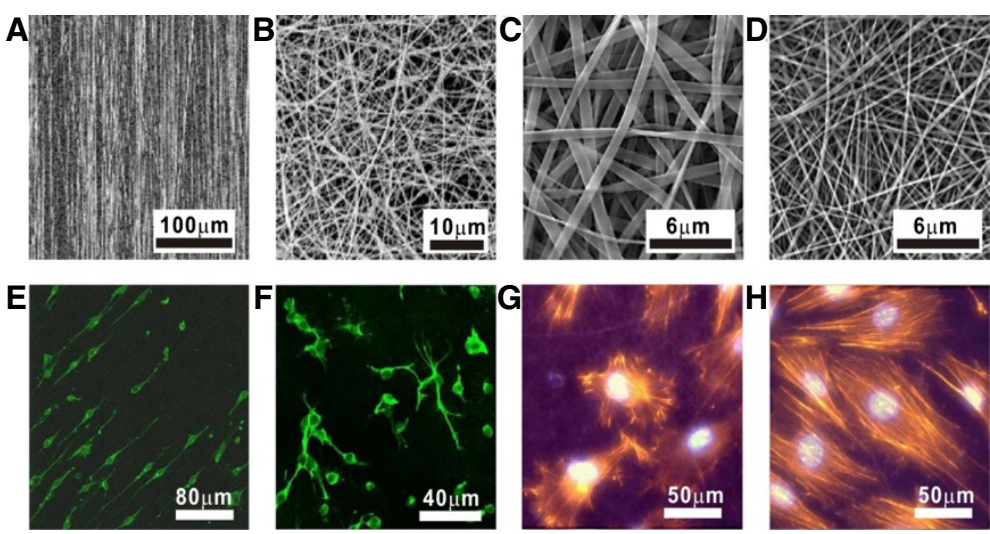

Figure 2 Polymer nanofibers for controlled cell growth. Scanning electron microscopy (SEM) images of (A) aligned PLLA nanofibers and (B) randomly-distributed PLLA nanofibers (reproduced from ref. 14 with permission, ( Elsevier). SEM images of PANi-gelatin blend nanofibers with its averaged diameters of (C) $803 \mathrm{~nm}$ and (D) $61 \mathrm{~nm}$. (reproduced from ref. 16 with permission, ( E) Elsevier). Immunofluorescence images of neurofilaments (green) in NSCS (E) on aligned PLLA nanofibers and (F) on randomly-distributed PLLA nanofibers (reproduced from ref. 14 with permission, $\odot$ Elsevier). Immunofluorescence images of actin filaments (red) and nuceli (blue) in myoblasts on the nanofibers with its averaged diameters of (G) $803 \mathrm{~nm}$ and (H) $61 \mathrm{~nm}$ (reproduced from ref. 16 with permission, @ Elsevier). 
[17]. Cell proliferation on polymer nanofibers was similar to that in a cell pellet culture which is a widely used cell culture system. However, the contents of sulfated glycosaminoglycan (sGAG) as a chondrogenic differentiation marker on polymer nanofibers was higher than that in a cell pellet culture. It indicates that the PCL nanofiber substrate supports a chondrogenic differentiation. MSCs were differentiated into osteoblasts on PCL nanofiber based scaffold in osteogenic differentiation medium as shown by Yoshimoto et al. [18] Cells migrated inside the polymer nanofiber-based scaffolds and produced an ECM of collagen after 1 week. MSCs on PCL nanofibers were also induced to differentiate along adipogenic, chondrogenic and osteogenic lineages in specific differentiation media [19]. Not only PCL but also poly (D,L-lactide-co-glycolide) (PLGA) and poly (L-lactic acid) (PLLA) support cell differentiation. Xin et al. reported hMSC on PLGA retained their phenotype and differentiated into chondrogenic and osteogenic cells in differentiation media [20].

Smith et al. examined the effect of nanofibrous scaffolds on osteogenic differentiation [21]. They prepared polymer nanofiber-based substrates in 2-D and 3-D formation. The nanofibrous structures in 2-D and 3-D enhanced the osteogenic differentiation of human embryonic stem cell (hESC)-derived osteogenic progenitor cells compared to the scaffolds without nanofibers.

The diameter of polymer nanofibers affects not only cell adhesion but also cell differentiation. Polyethersulfone (PES) nanofiber meshes with different diameter regulate proliferation and differentiation of rat neural stem cells (rNSCs) [22]. They used laminin-coated PES with diameters of $238 \pm 45 \mathrm{~nm}, 749 \pm 153 \mathrm{~nm}$ and $1452 \pm 312 \mathrm{~nm}$. As the diameter of polymer nanofibers decreases, cells were spread more on the nanofibers. rNSCs on $238 \mathrm{~nm}$ nanofiber mesh were spread on the nanofiber matrix, and they were assumed cell morphology of glial lineage. On the contrary, rNSCs on $749 \mathrm{~nm}$ nanofiber mesh adhered onto a single fiber, and they were elongated along a fiber axis. Those cells preferentially differentiated into neuronal lineage. However, both of cells on polymer nanofiber-based substrates showed the higher-level expression of the differentiation markers than those on a flat substrate.

Researchers also investigated the synergistic effect of polymer blends. $\mathrm{Ku}$ et al. invesgated the synergic effects of PCL and PANi blended nanofiber alignment on myoblast differentiations [23]. The differentiation of myoblasts on blended nanofibers was affacted by the PANi concentration. Kim et al. used commercial polymers to fabricate suitable biomaterial scaffold for the cell growth [24]. The modified PCL nanofibers incoporated within poly (ethylene oxide) (PEO) showed a good biocompatibility.

These results show that the polymer nanofiber can support multi-lineage differentiation capability of stem cells, and it is a good candidate for a scaffold in tissue regeneration or stem cell theraphy.

\subsection{Carbon-based nanotubes/nanofibers}

Carbon nanomaterials including carbon nanotubes (CNTs) and carbon nanofibers (CNFs) exhibit excellent mechanical and electrical properties. They have been explored in many biological applications such as bioelectronics, tissue engineering, cellular imaging and therapeutics $[9,25]$. The carbon nanomaterials can be advantageous for cell control because they do not emit ions and have a chemically-stable surface.

\subsubsection{Carbon nanotubes}

A CNT is a rolled-up graphene which is carbon atoms arranged in a planar honeycomb lattice. CNTs can be classified into single-walled CNT (swCNT) and multiwalled CNT (mwCNT) depending on the number of rolled-up graphene layers. Generally, the diameter of swCNT is about $1 \sim 2 \mathrm{~nm}$, and that of mwCNT varies from $2 \mathrm{~nm}$ to over $100 \mathrm{~nm}$ (Table 1). A CNT is mechanically strong and easy to be functionalized. The electrical and optical properties of CNTs can be used for various applicaions such as ultrasensitive biosensors. We review the recent applications of CNT-based substrates in controlling cell behaviors.

Nanoscale surface roughness of CNT-based substrates can deform cell membrane and hinder the motion of vesicles in cells. Zhang et al. reported that the areal coverage of vesicle motion was reduced in cells grown on a CNT layer, which was observed by total internal reflection fluorescence microscopy (Figure 3 (A)) [26]. Cellot et al. observed the improved postsynaptic current response of the neurons on CNTs [27]. The intimate contact between cell membranes and CNTs provided a close electrical coupling of the neurons and CNTs, which could directly stimulate neural activities (Figure 3 (B)). Furthermore, the spinal cord explants interfaced to CNT scaffolds for long-term period increased the number and length of neuronal fiber outgrowing spinal segments. This study also showed that CNT scaffolds augmented synaptic response in neurons located as far as 5 cell layers from the cell-substrate interactions.

Patterned CNTs on substrates can control the shapes or orientiations of cells. Park et al. succeeded in aligning hMSCs along the patterned CNTs [28]. In this work, CNTs were selectively assembled on the substrate using the pre-patterned hydrophobic SAM molecules. The selective binding of ECM proteins (e.g. fibronectin) onto CNT regions could lead the hMSCs to grow along the CNT pattern. In a similar way, Jang et al. showed highly directional growth of neurites along the line-shape CNT patterns after 14 days of rat hippocampal neuron culture, 

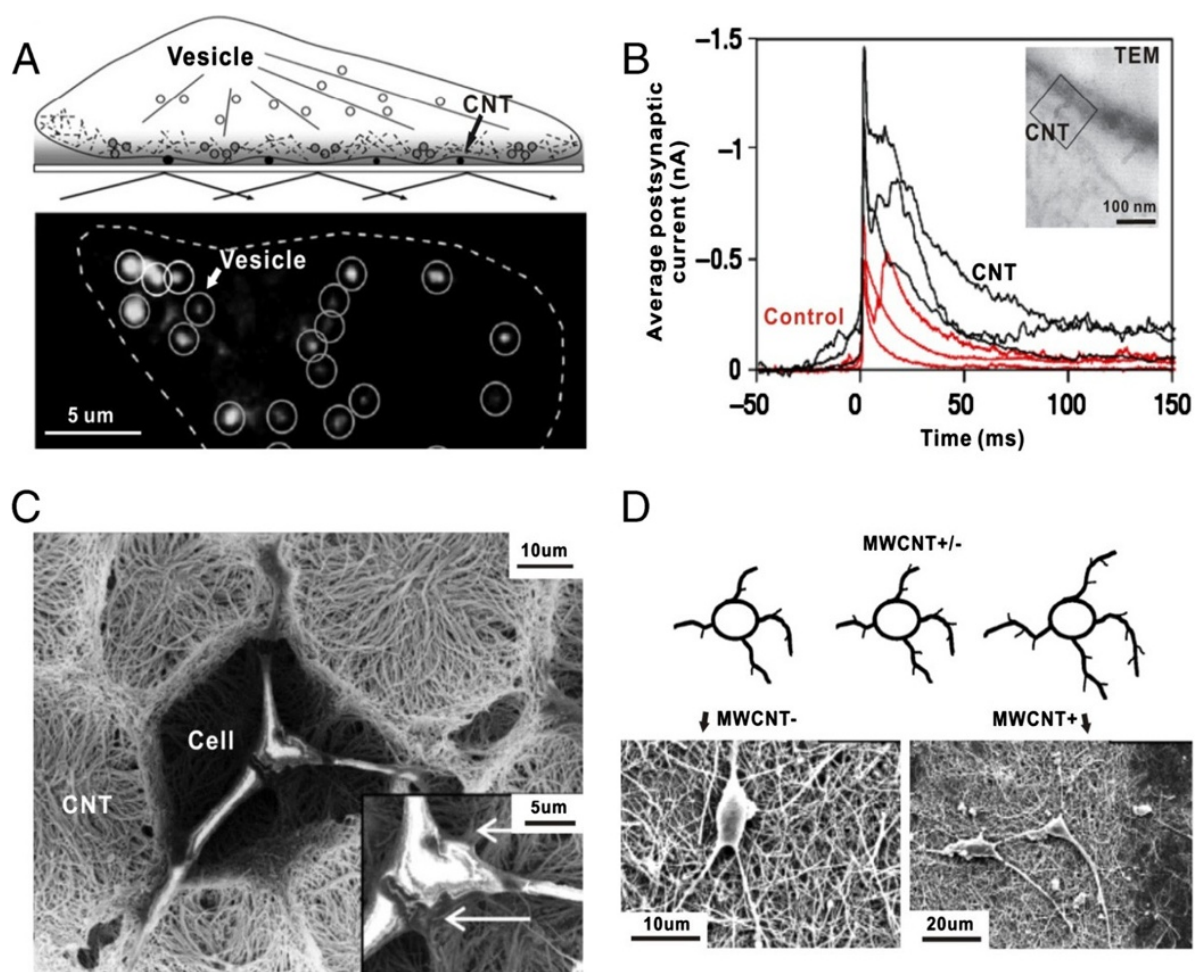

Figure 3 CNT-based substrates for controlling and monitoring cell behaviors. (A) An immunofluorescence image of secretory vesicles inside a cell on a CNT-based substrate with a schematic diagram (reproduced from ref. 26 with permission, ( ) Wiley-VCH). (B) The computed waveforms of the average postsynaptic currents from the neurons on a CNT-based substrate (reproduced from ref. 27 with permission, $\odot$ Nature Publishing Group). (C) SEM images of a fibroblast (white arrows) cultured on a 3-D CNT structure (reproduced from ref. 32 with permission, $\odot$ American Chemical Society). (D) SEM images of neurons on positively and negatively charged mwCNTs (reproduced from ref. 33 with permission, ๑ American Chemical Society).

which was attributed to the higher density adsorption of poly-L-lysine on the CNT patterns [29].

Previously, proteins have been known nonspecifically adsorbed well on sidewall of CNTs. Shim et al. demonstrated that the high affinity of proteins on CNTs could be attributed to the hydrophobic nature of CNTs or the pi-pi bonding between CNTs and proteins [30]. The adsorbed proteins mediated the interaction between cells and CNTs for a improved adhesion.

Aligned CNTs on substrates are useful in accelerating cell migration which is important in regeneration medicine. Galvan-garcia et al. assembled highly oriented mwCNT sheets and yarns, and they observed the directed cell growth along the CNTs [31]. In this work, the migration of fibroblasts on CNT sheets was enhanced, and the cell proliferation speed on the CNT sheets was comparable to that on glass. They also observed the directed neuronal growth along the CNT yarns, closely following the surface topography of the substrate.

A 3-D structure of CNT-film networks was explored for tissue engineering. Correa-Duarte et al. transformed a vertically-aligned structure of mwCNTs to a regular 3-D sieve structure by using chemically induced capillary forces
(Figure $3(\mathrm{C})$ ) [32]. They successfully demonstrated that the controlled growth of a mouse fibroblast cell line (L929) in this 3-D CNT structure.

Surface functionalized CNTs provide great opportunities in controlling cell growth. Hu et al. reported that chemically modified CNTs affected the outgrowth and branching patterns of neurons [33]. The results showed that the positive charges induced more numerous growth cones, longer average neurite length and more neurite branching than the groups with neutral and negative charges (Figure 3 (D)). Zanello et al. cultured osteoblast (ROS 17/2.8) cells on the CNTs with various functional groups [34]. They found the highest cell growth on electrically-neutral swCNTs (as-produced-swCNT and swCNT-PEG). On the other hand, the lowest cell growth was observed on CNTs with charged groups (swCNT-COOH and swCNT-poly (m-aminobenzene sulfonic acid)).

CNTs can be used to transmit electrical stimulation to neural cells. Wang et al. developed a prototype of neural interface using vertically aligned mwCNT pillars [35]. The neurons were grown and differentiated on the hydrophilic functionalized CNT microelectrodes, and they were 
repeatedly excited with charge-unbalanced stimulation protocols. In this study, the CNT electrodes operated predominantly with capacitive currents without faradic reactions, which were considered ideal for neural stimulations.

CNTs were also explored to control cell differentiation. Tay et al. cultured hMSCs on a thin layer of carboxylic functionalized swCNTs with a vertical height of less than $100 \mathrm{~nm}$ [36]. In this report, they showed that the neurogenic genes were increased while osteogenic genes remained at a nominal level. This result suggests that CNT nano-roughness alone was sufficient to modulate the early stage of stem cell lineage commitment without the aid of induction media.

Some researchers performed experimental studies to reveal the mechanisms for the different differentiation behaviors of cells on CNTs. Namgung et al. investigated the enhanced differentiation of hMSCs on the aligned CNT networks [37]. They found that up-regulaed gene expressions of hMSCs related to the mechanotransduction pathways. These results supported that the high cytoskeletal tension of hMSCs could promote the differentiation of cells. Chen et al. suggested that the concentrated human bone marrow mesenchymal stem cells (hBMMSCs) following the carboxylated mwCNTs can up-regulate the secretion of growth factors [38].

\subsubsection{Carbon nanofibers}

Carbon nanofibers (CNFs) are graphene layers arranged as stacked cones, cups or plates, and their diameter ranges from $3.5 \mathrm{~nm}$ to $500 \mathrm{~nm}$ (Table 1) [9]. CNFs have been also explored widely in tissue engineering with the combination of polymers.

The topographical effects of CNFs were investigated in cells. McKenzie et al. prepared a CNF and polycarbonate urethane (PCU) composite substrate with different diameters of CNFs ranging from $60 \mathrm{~nm}$ to $200 \mathrm{~nm}$ [39]. They found that astrocytes preferentially adhered and proliferated on CNFs with the largest diameter. Price et al. demonstrated that this CNF-PCU substrates promoted the adhesion of osteoblasts, but the adhesions of smooth muscle cells, fibroblasts, and chondrocytes were not influenced [40].

Khang et al. examined osteoblast adhesion on microscale CNF patterns (30- $\mu \mathrm{m}$-width line) on polymer substrates [41]. The patterns of CNFs on PCU substrate were prepared using an imprinting method. Osteoblasts selectively adhered and aligned on CNF patterns on PCU. The greater attractive forces between fibronectin and CNF (compared with $\mathrm{PCU}$ ) measured by an atomic force microscope gave a plausible explanation for the selective cell adhesion.

\subsection{Inorganic nanowires/nanotubes}

Inorganic nanowires/nanotubes have been commonly exploited as effective tools for controlling cell behaviors by delivering biomolecules into the cells [42] and sensing intra/extracellular signals $[43,44]$. In addition, inorganic nanowires/nanotubes based substrates are utilized as platforms to investigate the effect of nanoscale substrate topography and size-dependent cellular responses [45-47]. Furthermore, inorganic nanowires/nanotubes have been also utilized for various other cellular applications such as controlling cell position, measuring cellular forces or sensing cellular activities. Inorganic nanowires/ nanotubes could be synthesized with a variety of materials including titanium oxide $\left(\mathrm{TiO}_{2}\right)$, zinc oxide $(\mathrm{ZnO})$, silicon (Si), etc. The synthesis methods include CVD $[48,49]$, anodization [50], electrochemical deposition [51] and solvothermal growth [52]. Inorganic nanowires/ nanotubes are rather easy to adjust their nanoscale surface topology and chemical properties for the control of cell behaviors.

\subsubsection{Titanium oxide nanotubes}

The interaction between cells and titanium oxide substrates has been extensively investigated for clinical implant applications. Recent studies showed that the nanoscale modulation of $\mathrm{TiO}_{2}$ surface topography enhanced the efficiency in implantation. In this study, vertically-grown $\mathrm{TiO}_{2}$ nanotubes have been used as an effective scaffold to provide various nanoscale geometries, because the diameter of $\mathrm{TiO}_{2}$ nanotubes is easily controlled in the synthesis process.

Park et al. demonstrated responses of rat MSCs on vertically-oriented and highly-ordered $\mathrm{TiO}_{2}$ nanotubes. $\mathrm{TiO}_{2}$ nanotubes were fabricated on titanium surface by the anodization process, and the diameter of $\mathrm{TiO}_{2}$ nanotubes were varied from $15 \mathrm{~nm}$ to $100 \mathrm{~nm}$ by controlling the applied voltage (Figure 4 (A)). They showed significantlyenhanced cellular activities such as adhesion, proliferation and differentiation on $15 \mathrm{~nm} \mathrm{TiO}_{2}$ nanotubes compared to $70 \mathrm{~nm}-100 \mathrm{~nm} \mathrm{TiO}_{2}$ nanotubes, which was attributed to the accelerated formation of integrin clustering and focal contact [45]. In other work, the similar results of the enhanced cellular activities on $15 \mathrm{~nm} \mathrm{TiO}_{2}$ nanotubes were shown with hematopoietic stem cells (HSCs) (Figure $4(\mathrm{~B})$ and $(\mathrm{C})$ ) [46].

They continued experiments with various types of cells to address the dominant factors determining cell fates on $\mathrm{TiO}_{2}$ nanotubular enviroment [47]. Three different types of cells (endothelial cell line mlEND, hMSCs and human cord blood endothelial progenitor cells) related to blood vessel formation were studied with respect to the diameter, the crystalline structure and the chemical composition of $\mathrm{TiO}_{2}$ nanotubes. As the diameter of $\mathrm{TiO}_{2}$ nanotubes decreased, the cell adhesion and proliferation were enhanced regardless of the cell type. The crystalline structure and the chemical composition of $\mathrm{TiO}_{2}$ nanotubes did not affect significantly on cell behaviors, 


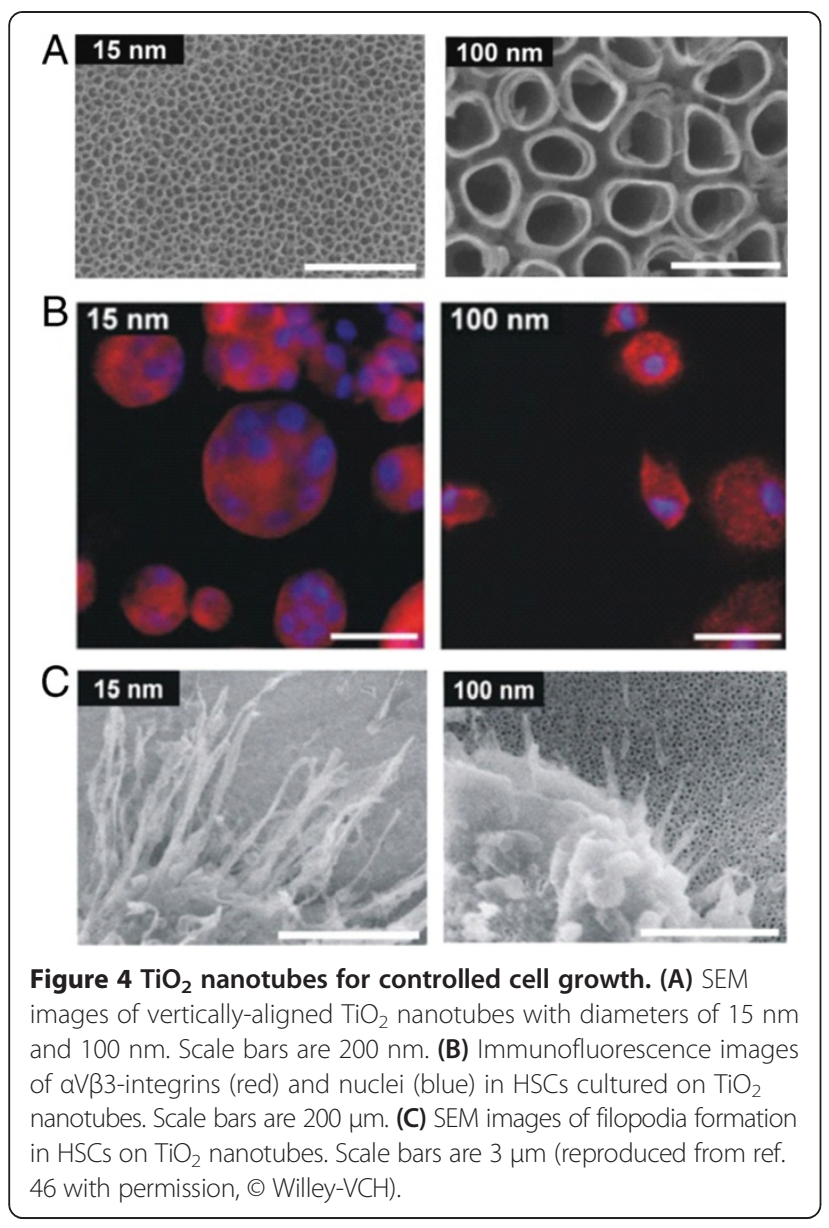

which strongly suggests that the nanotopography should be a dominant factor for cell growth.

However, the results from Oh et al. were in conflict with previous experiments [50]. They observed that the differentiation of hMSCs into osteoblast-like cells was enhanced on $\mathrm{TiO}_{2}$ nanotubes with larger diameters $(70 \mathrm{~nm}$ to $100 \mathrm{~nm}$ ) rather than smaller diameters $(30 \mathrm{~nm}$ to $50 \mathrm{~nm}$ ) in the absence of osteogenic inducing factors. These findings suggest that finely-tuned nanotopography of $\mathrm{TiO}_{2}$ nanotubes could determine the cell fate, even though there are still controversies regarding the optimal diameter of $\mathrm{TiO}_{2}$ nanotubes for the enhanced cell adhesion, proliferation and differentiation.

\subsubsection{Zinc oxide nanowires}

Zinc oxide nanowires ( $\mathrm{ZnO} \mathrm{NWs}$ ) are also attractive nanostructures due to their semiconducting and piezoelectric properties, and they have been utilized for biosensors [53] and other biomedical applications [54]. The cell adhesion and proliferation on $\mathrm{ZnO}$-based nanostructures have been also demonstrated. Lee et al. explored the cell adhesion and growth on vertically-grown $\mathrm{ZnO}$ NWs with NIH3T3 fibroblasts, umbilical vein endothelial cells and capillary endothelial cells (Figure 5 (A))
[55]. In this case, the $\mathrm{ZnO} \mathrm{NWs}$ were hydrothermally grown on the uniformly distributed $\mathrm{ZnO}$ nano-seeds. $\mathrm{ZnO} \mathrm{NWs}$ are approximately $50 \mathrm{~nm}$ in diameter and $500 \mathrm{~nm}$ in height. The cells on $\mathrm{ZnO}$ NWs showed weaker adhesion and lower viability than cells on a flat $\mathrm{ZnO}$ substrate. The authors attributed the poor adhesion and proliferation of cells on the vertically grown nanowires to the hindrance in focal adhesion formation. Simply speaking, there was not enough space for the integrin clustering on $\mathrm{ZnO} \mathrm{NWs}$, which induced poor cell adhesion and proliferation. Zaveri et al. also reported similar results on $\mathrm{ZnO}$ NWs with macrophage cells [56]. In addition, in this work, the cytotoxic effects of solubilized $\mathrm{ZnO}$ NWs were additionally revealed.

On the contrary, it was reported that the enhanced cell adhesion, proliferation and differentiation on $\mathrm{ZnO}$ nanoflowers (Figure 5 (B)) [57]. In this work, the $\mathrm{ZnO}$ nanoflowers were also grown by the hydrothermal methods on the micro-patterned $\mathrm{ZnO}$ surface. The nanoflowers were comprised of $\mathrm{ZnO} N W s$ with $200 \sim 300 \mathrm{~nm}$ in diameter and $3 \sim 4 \mu \mathrm{m}$ in length. In this platform, osteoblasts on $\mathrm{ZnO}$ nanoflowers showed stronger adhesion, more DNA content and higher ALP activity than those on the flat $\mathrm{ZnO}$ surface. Furthermore, $\mathrm{ZnO}$ nanoflowers were tightly osseointegrated with the regenerated bones in the calvarial bone defects of Sprague Dawley rats. The results were attributed to the enhanced formation of lamellipodia, filopodia, and F-actin filaments on the surface of $\mathrm{ZnO}$ nanoflowers.

\subsubsection{Other inorganic nanowires}

The control of cell adhesion and viability has been also demonstrated on various other nanowires. The effects depend on the physical and chemical properties of nanowires. Of interest, the unique properties of each nanowire allow additional cellular applications. For example, dissociated sensory neurons cultured on vertically-grown epitaxial gallium phosphide nanowires (GaP NWs) showed a higher viability than planar gallium phosphide substrates (Figure 5 (C)) [58]. Interestingly, in other work, GaP NWs were utilized to measure cellular forces by analyzing the bending of GaP NWs (Figure 5 (D)) [59]. The rigidity, the high aspect ratio, and the nanoascale dimension of GaP NWs allow spatially-resolved and sensitive measurements of cellular forces.

Johansson et al. investigated the effect of nickel nanowires (Ni NWs) on L929 mouse fibroblasts and dissociated dorsal root ganglia (DRG) neurons [60]. They synthesized Ni NWs by the alumina template based electro-deposition method, which were $200 \mathrm{~nm}$ in diameter and $40 \mu \mathrm{m}$ in length. They aligned Ni NWs using their magnetic property, and the cells were grown over the aligned Ni NWs. They showed that the cells displayed the contact guidance along the aligned Ni NWs. 

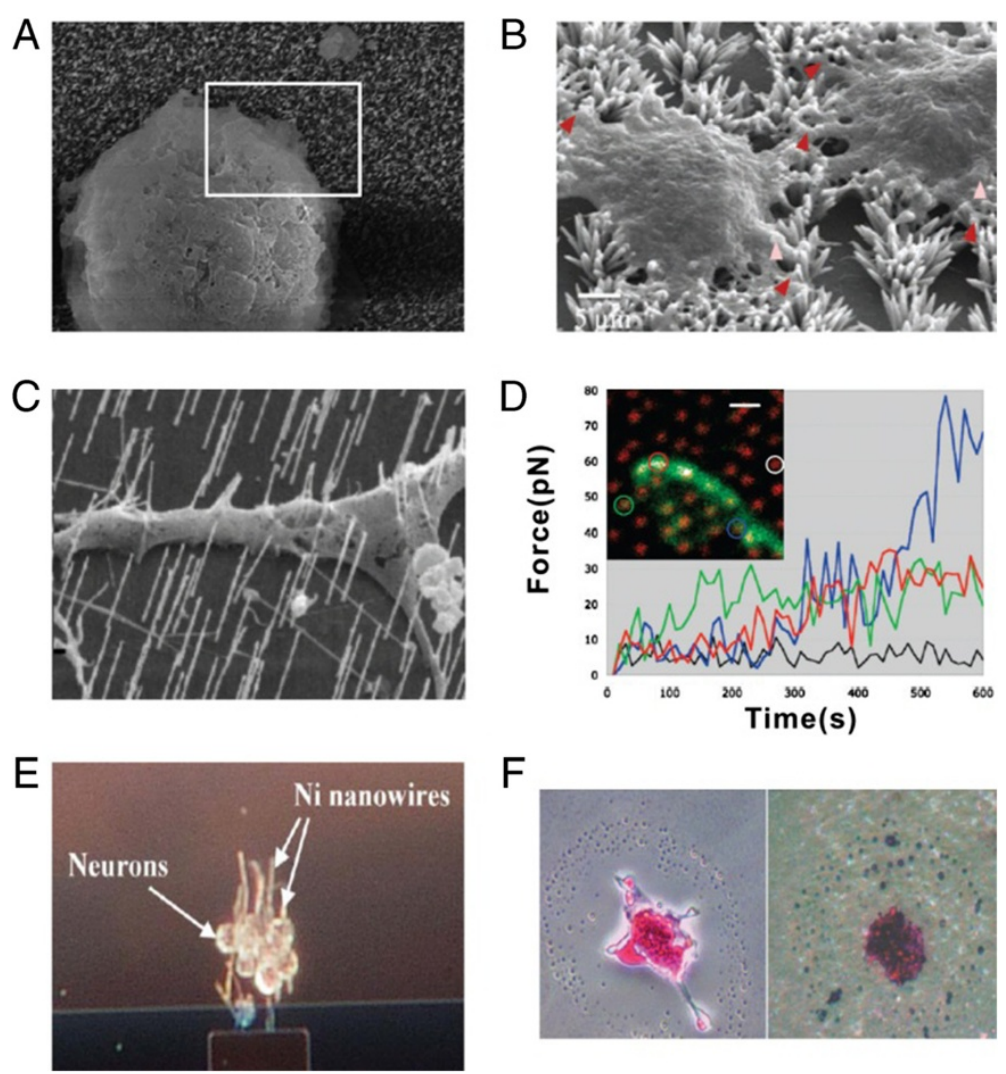

$\mathrm{F}$

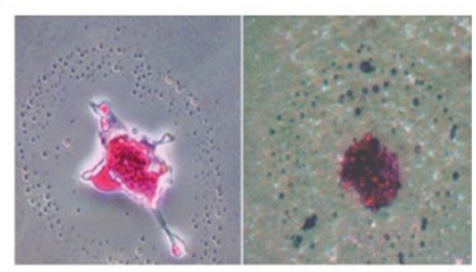

Figure 5 Various inorganic nanowires for controlling and monitoring cell behaviors. (A) A SEM image of NIH3T3 fibroblasts on ZnO NWs with a poor adhesion compared to the flat ZnO surface (reproduced from ref. 55 with permission, ( E Elsevier). (B) A SEM image of MC3T3-E1 osteoblasts grown on $\mathrm{ZnO}$ nanoflowers with an enhanced adhesion compared to the flat ZnO surface. Lamellipodia and filopodia were indicated with pink and red arrowheads, respectively (reproduced from ref. 57 with permission, @ Wiley-VCH). (C) Neurons grown on vertically-grown GaP NWs (reproduced from ref. 59 with permission, ( ) American Chemical Society). (D) The forces of a neural growth cone measured with the four GaP NWs (circles using the same color coding in the inset image). The black curve corresponds to the noise obtained by measuring the deflection of a nanowire that was not in contact with a cell (the white circle in inset image). The inset image shows neural growth cone on vertically-ordered GaP NW arrays. A scale bar is $1 \mu \mathrm{m}$ (reproduced from ref. 58 with permission, @ American Chemical Society). (E) An optical micrograph image of the cells internalized by Ni NWs. Ni NWs transported by an external magnetic field to the gap between the ferromagnetic electrode and the gold electrode (reproduced from ref. 62 with permission, $\odot$ Springer). (F) Phase contrast images of differentiated stem cells on a flat RGD-treated gold surface (left) and on RGD-treated Au NWs (right). Oil red O staining was used for visualizing adipogenic differentiation (reproduced from ref. 63 with permission, $\odot$ Royal Society of Chemistry).

In other works, the magnetic properties of Ni NWs were utilized for the cell separation [61] or the cell positioning (Figure $5(E)$ ) [62].

The adhesion and the differentiation of MSCs on gold nanowires (Au NWs) were also demonstrated by Luo et al. [63]. The well-known chemistry on Au surface allowed functionalization of $\mathrm{Au}$ NWs with self-assembled monolayers containing diverse functional groups. In this work, Au NWs were functionalized with a cell adhesive peptide (RGD- ONH2). As a result, MSCs on the functionalized $\mathrm{Au}$ NWs showed more fillopodia extensions compared to those on flat gold surfaces functionalized with the same RGD peptides. Moreover, in the process of adipogenic differentiation, the enhanced differentiation was observed on Au NWs (Figure 5 (F)).
$\mathrm{Al} / \mathrm{Al}_{2} \mathrm{O}_{3}$ core/shell nanowires and patterned Si nanopillars were also studied to control the cellular responses such as cell adhesion, growth and proliferation. Lee et al. patterned periodic structures of $\mathrm{Al} / \mathrm{Al}_{2} \mathrm{O}_{3}$ core/shell nanowires, and showed that the periodic patterns lead to the alignment of glial cells and dorsal root ganglia axons [64]. Similar to the $\mathrm{Al} / \mathrm{Al}_{2} \mathrm{O}_{3}$ nanowires experiment, Bucaro et al. showed that Si nanopillars could control the cell polarization and alignment by controlling the radius, height and interpillar spacing of Si nanopillars [65].

\section{Conclusions}

In summary, we discussed various synthetic nanowires/ nanotubes utilized in cell engineering. Since it is easy to control the diameter, mechanical property and surface 
chemistry of synthetic nanowires/nanotubes, they can be utilized to create active microenvironments to control cell behaviors. Moreover, the nanowire/nanotube-based functional devices can be used as intercellular drug delivery system and ultrasensitive biosensors for real-time detection of cell activities. Although their cytotoxicity is still under debate and requires more systematic studies, synthetic nanowires/nanotubes have great potentials not only in fundamental research but also in clinical applications such as drug screening devices, organ-on-a chips and medical tissue grafts. With the advances in nanomaterials and manipulating technique, the synthetic nanowire/nanotube based system should provide enormous opportunities in biomedical applications.

\section{Competing interests}

The authors declare that they have no competing interests.

\section{Authors' contributions}

All authors have contributed to the writing of the manuscript. All authors read and approved the final manuscript.

\section{Acknowledgement}

SH acknowledges the support from the BioNano Health Guard Research Center (H-GUARD_2013M3A6B2078961) and the NRF grant (No. 2013-007874).

\begin{abstract}
Author details
${ }^{1}$ Department of Electrical and Biological Physics, Kwangwoon University, Seoul 139-701, Korea. ${ }^{2}$ Center for Functional Connectomics, Korea Institute of Science and Technology, Hwarangno 14-gil 5, Seongbuk-gu, Seoul 136-791, Korea. ${ }^{3}$ Department of Electrical and Computer Engineering, University of Minnesota, Minneapolis, MN 55455, USA. ${ }^{4}$ Department of Biophysics and Chemical Biology, Seoul National University, Seoul 151-747, Korea. ${ }^{5}$ Department of Physics and Astronomy, and Institute of Applied Physics, Seoul National University, Seoul 151-747, Korea.
\end{abstract}

Received: 27 August 2014 Accepted: 15 September 2014 Published online: 04 November 2014

\section{References}

1. E.S. Place, N.D. Evans, M.M. Stevens, Nat. Mater. 8, 457-470 (2009)

2. O. Guillame-Gentil, O. Semenov, A.S. Roca, T. Groth, R. Zahn, J. Voros, M. Zenobi-Wong, Adv. Mater. 22, 5443-5462 (2010)

3. D.O. Freytes, L.Q. Wan, G. Vunjak-Novakovic, J. Cell. Biochem. 108, 1047-1058 (2009)

4. M.P. Lutolf, P.M. Gilbert, H.M. Blau, Nature 462, 433-441 (2009)

5. O.Z. Fisher, A. Khademhosseini, R. Langer, N.A. Peppas, Accounts Chem. Res 43, 419-428 (2010)

6. M.P. Lutolf, J.A. Hubbell, Nat. Biotechnol. 23, 47-55 (2005)

7. E. Dawson, G. Mapili, K. Erickson, S. Taqvi, K. Roy, Adv. Drug Deliv. Rev. 60, 215-228 (2008)

8. S.H. Lim, H.Q. Mao, Adv. Drug Deliv. Rev. 61, 1084-1096 (2009)

9. P.A. Tran, L.J. Zhang, TJ. Webster, Adv. Drug Deliv. Rev. 61, 1097-1114 (2009)

10. Z. Li, J.H. Song, G. Mantini, M.Y. Lu, H. Fang, C. Falconi, L.J. Chen, Z.L. Wang, Nano Lett. 9, 3575-3580 (2009)

11. A. Martins, A.R.C. Duarte, S. Faria, A.P. Marques, R.L. Reis, N.M. Neves, Biomaterials 31, 5875-5885 (2010)

12. T. Cohen-Karni, B.P. Timko, L.E. Weiss, C.M. Lieber, Proc. Natl. Acad. Sci. U. S. A. 106, 7309-7313 (2009)

13. S. Patel, K. Kurpinski, R. Quigley, H.F. Gao, B.S. Hsiao, M.M. Poo, S. Li, Nano Lett. 7, 2122-2128 (2007)

14. F. Yang, R. Murugan, S. Wang, S. Ramakrishna, Biomaterials 26, 2603-2610 (2005)

15. B.M. Baker, R.L. Mauck, Biomaterials 28, 1967-1977 (2007)

16. M.Y. Li, Y. Guo, Y. Wei, A.G. Macdiarmid, P.I. Lelkes, Biomaterials 27, 2705-2715 (2006)
17. W.J. Li, R. Tuli, C. Okafor, A. Derfoul, K.G. Danielson, D.J. Hall, R.S. Tuan, Biomaterials 26, 599-609 (2005)

18. H. Yoshimoto, Y.M. Shin, H. Terai, J.P. Vacanti, Biomaterials 24, 2077-2082 (2003)

19. W.J. Li, R. Tuli, X.X. Huang, P. Laquerriere, R.S. Tuan, Biomaterials 26, 5158-5166 (2005)

20. X.J. Xin, M. Hussain, J.J. Mao, Biomaterials 28, 316-325 (2007)

21. L.A. Smith, X.H. Liu, J.A. Hu, P.X. Ma, Biomaterials 31, 5526-5535 (2010)

22. G.T. Christopherson, H. Song, H.Q. Mao, Biomaterials 30, 556-564 (2009)

23. S.H. Ku, S.H. Lee, C.B. Park, Biomaterials 33, 6098-6104 (2012)

24. S.E. Kim, J. Wang, A.M. Jordan, L.T.J. Korley, E. Baer, J.K. Pokorski, ACS Macro Lett. 3, 585-589 (2014)

25. K. Kostarelos, A. Bianco, M. Prato, Nat. Nanotechnol. 4, 627-633 (2009)

26. J. Zhang, D.L. Fu, M.B. Chan-Park, L.J. Li, P. Chen, Adv. Mater. 21, 790-793 (2009)

27. G. Cellot, E. Cilia, S. Cipollone, V. Rancic, A. Sucapane, S. Giordani, L. Gambazzi, H. Markram, M. Grandolfo, D. Scaini, F. Gelain, L. Casalis, M. Prato, M. Giugliano, L. Ballerini, Nat. Nanotechnol. 4, 126-133 (2009)

28. S.Y. Park, S. Namgung, B. Kim, J. Im, Y. Kim, K. Sun, K.B. Lee, J.M. Nam, Y. Park, S. Hong, Adv. Mater. 19, 2530-2534 (2007)

29. M.J. Jang, S. Namgung, S. Hong, Y. Nam, Nanotechnology 21, 235102 (2010)

30. M. Shim, N.W.S. Kam, R.J. Chen, Y.M. Li, H.J. Dai, Nano Lett. 2, 285-288 (2002)

31. P. Galvan-Garcia, E.W. Keefer, F. Yang, M. Zhang, S. Fang, A.A. Zakhidov, R.H. Baughman, M.I. Romero, J. Biomater. Sci.-Polym. Ed. 18, 1245-1261 (2007)

32. M.A. Correa-Duarte, N. Wagner, J. Rojas-Chapana, C. Morsczeck, M. Thie, M. Giersig, Nano Lett. 4, 2233-2236 (2004)

33. H. Hu, Y.C. Ni, V. Montana, R.C. Haddon, V. Parpura, Nano Lett. 4, 507-511 (2004)

34. L.P. Zanello, B. Zhao, H. Hu, R.C. Haddon, Nano Lett. 6, 562-567 (2006)

35. K. Wang, H.A. Fishman, H.J. Dai, J.S. Harris, Nano Lett. 6, 2043-2048 (2006)

36. C.Y. Tay, H.G. Gu, W.S. Leong, H.Y. Yu, H.Q. Li, B.C. Heng, H. Tantang, S.C.J. Loo, L.J. Li, L.P. Tan, Carbon 48, 1095-1104 (2010)

37. S. Namgung, K.Y. Baik, J. Park, S. Hong, ACS Nano 5, 7383-7390 (2011)

38. Y.S. Chen, G.H. Hsiue, Biomaterials 34, 4936-4944 (2013)

39. J.L. Mckenzie, M.C. Waid, R.Y. Shi, T.J. Webster, Biomaterials 25, 1309-1317 (2004)

40. R.L. Price, K. Ellison, K.M. Haberstroh, T.J. Webster, J. Biomed. Mater. Res. Part A 70A, 129-138 (2004)

41. D. Khang, M. Sato, R.L. Price, A.E. Ribbe, T.J. Webster, Int. J. Nanomed 1, 65-72 (2006)

42. A.K. Shalek, J.T. Robinson, E.S. Karp, J.S. Lee, D.R. Ahn, M.H. Yoon, A. Sutton, M. Jorgolli, R.S. Gertner, T.S. Gujral, G. Macbeath, E.G. Yang, H. Park, Proc. Natl. Acad. Sci. U. S. A. 107, 1870-1875 (2010)

43. F. Patolsky, B.P. Timko, G.H. Yu, Y. Fang, A.B. Greytak, G.F. Zheng, C.M. Lieber, Science 313, 1100-1104 (2006)

44. B.Z. Tian, T. Cohen-Karni, Q. Qing, X.J. Duan, P. Xie, C.M. Lieber, Science 329, 830-834 (2010)

45. J. Park, S. Bauer, K. Von Der Mark, P. Schmuki, Nano Lett. 7, 1686-1691 (2007)

46. J. Park, S. Bauer, K.A. Schlegel, F.W. Neukam, K. Von Der Mark, P. Schmuki, Small 5, 666-671 (2009)

47. J. Park, S. Bauer, P. Schmuki, K. Von Der Mark, Nano Lett. 9, 3157-3164 (2009)

48. K. Heo, C.J. Kim, M.H. Jo, S. Hong, J. Mater. Chem. 19, 901-908 (2009)

49. W.I. Park, J. Yoo, J. GC Yi, Korean Phys. Soc 46, L1067-L1070 (2005)

50. S. Oh, K.S. Brammer, Y.S.J. Li, D.Y. Teng, A.J. Engler, S. Chien, S.H. Jin, Proc. Natl. Acad. Sci. U. S. A. 106, 2030-2135 (2009)

51. C.R. Martin, Science 266, 1961-1966 (1994)

52. G.F. Zou, H. Li, Y.G. Zhang, K. Xiong, Y.T. Qian, Nanotechnology 17, S313-S320 (2006)

53. P.H. Yeh, Z. Li, Z.L. Wang, Adv. Mater. 21, 4975-4978 (2009)

54. Z. Li, R.S. Yang, M. Yu, F. Bai, C. Li, Z.L. Wang, J. Phys. Chem. C 112, 20114-20117 (2008)

55. J.Y. Lee, B.S. Kang, B. Hicks, T.F. Chancellor, B.H. Chu, H.T. Wang, B.G. Keselowsky, F. Ren, T.P. Lele, Biomaterials 29, 3743-3749 (2008)

56. T.D. Zaveri, N.V. Dolgova, B.H. Chu, J.Y. Lee, J.E. Wong, T.P. Lele, F. Ren, B.G. Keselowsky, Biomaterials 31, 2999-3007 (2010)

57. J.K. Park, Y.J. Kim, J. Yeom, J.H. Jeon, G.C. Yi, J.H. Je, S.K. Hahn, Adv. Mater. 22, 4857-4861 (2010)

58. W. Hallstrom, M. Lexholm, D.B. Suyatin, G. Hammarin, D. Hessman, L Samuelson, L. Montelius, M. Kanje, C.N. Prinz, Nano Lett. 10, 782-787 (2010)

59. W. Hallstrom, T. Martensson, C. Prinz, P. Gustavsson, L. Montelius, L. Samuelson, M. Kanje, Nano Lett. 7, 2960-2965 (2007) 
60. F. Johansson, M. Jonsson, K. Alm, M Kanje. Exp. Cell Res. 316, 688-694 (2010)

61. N. Gao, H.J. Wang, E.H. Yang, Nanotechnology 21, 105107 (2010)

62. D. Choi, A. Fung, H. Moon, D. Ho, Y. Chen, E. Kan, Y. Rheem, B. Yoo, N. Myung, Biomed. Microdevices 9, 143-148 (2007)

63. W. Luo, M.N. Yousaf, Chem. Commun. 1237-1239 (2009)

64. J. Lee, L.K. Schwarz, C.K. Akkan, M.M. Miró, O.T. Abad, K.-H. Schäfer, M. Veith, C. Aktas, Phys. Status Solidi A-Appl. Mat. 210, 952-956 (2013)

65. M.A. Bucaro, Y. Vasquez, B.D. Hatton, J. Aizenberg, ACS Nano 6, 6222-6230 (2012)

doi:10.1186/s40580-014-0028-0

Cite this article as: Baik et al:: Synthetic nanowire/nanotube-based solid substrates for controlled cell growth. Nano Convergence 2014 1:28.

Submit your manuscript to a SpringerOpen ${ }^{\circ}$ journal and benefit from:

- Convenient online submission

- Rigorous peer review

- Immediate publication on acceptance

- Open access: articles freely available online

- High visibility within the field

- Retaining the copyright to your article

Submit your next manuscript at $\gg$ springeropen.com 